\title{
Service quality and user satisfaction in academic libraries: perspectives from Sri Lankan universities.
}

\author{
[ I.M. Nawarathne ]
}

\begin{abstract}
The aim of this study was to consider the quality of academic library services from the customers' point of view in Sri Lankan academic libraries. Primary objective of academic library is user satisfaction and it is scaffolding with formal higher studies. Satisfaction is the consumer's good judgment about pleasure versus displeasure. In every academic year, new students enter the university with various educational needs and expectations under the vivid disciplines. Students are oriented to familiar with library resources. As a new technological development, researchers are made well equipped with the new innovative systems for accessing quality information in a fast manner. These innovative systems present challenges not only for librarians but also for students. Such new influx systems must be identified earlier and the library should train its users to adapt such newly implemented environment. User satisfaction is an important part of service quality measurement method in academic libraries. While applying service quality measurement method, feedback from users can be assessed and the available services can be improved. Special characteristics were identified during process of survey for service quality. It has decreased the standard of significant services necessarily available in libraries. In this analysis, all those necessary services that are vital for obtaining day to day fresh information and have been deteriorated in university libraries were found out. It was also identified that the mean median and mode scores of services/facilities such as ventilation in the library, relevant text books on various subjects, the range of printed journals, the range of e-journals, number of subscribed databases, number of service hours and printing facilities were considerably low.
\end{abstract}

Keywords- Academic libraries, Service quality, user satisfaction, library management

\author{
I.M.Nawarathne \\ Sabaragamuwa university of Sri Lanka
}

\section{Introduction}

The service quality of an academic library is a very significant factor as user satisfaction is based on service quality offered by the library. Service quality of academic library is a vital factor for any university which is service oriented. Their survival and reputation of library solely depend on the standard of services. Libraries can be regarded as non-profit institutions and based on activities and output of services. Users are the purpose of a library and therefore, best assessors of service standard in libraries are their users. In an academic library, students and administrators of the faculty are the customers or patrons or users. Each one's expectation is different [1] [2]. Companies expect profit for the services or goods supplied by them and primarily they measure the return according to the investment. In the same manner, libraries produce information to the society. The value or return on investment delivered by libraries is of a social, educational or cultural value and this is not easy to measure [3]. Even though the functions are similar but the output is different. According to the Nitecki [4], the traditional indicators which were used to measure the service quality of academic libraries like the size of collections has become outdated when meeting the demands of modern society and academic communities. Service quality is a form of attitude and not equivalent to satisfaction of the users.

\section{Studies relevant to Sri Lankan University libraries}

In the past, service oriented organizations such as hospitals, schools and libraries were not concerned with marketing their services. The reason behind this state of affairs was that there was no competition among these services. But at present, this scenario is completely changed. Every organization needs to market their services in the competitive contemporary circumstances. Therefore, it is necessary to utilize developed marketing strategies to market their services. Otherwise it will gravely affect the survival of such institutions rather than development. Specially maintaining a higher quality services is a vital tool to face the modern-day challenges. Success of service marketing strategy is highly dependable on 
Proc. of The Second Intl. Conf. On Advances In Economics, Social Science and Human Behaviour Study - ESSHBS 2015 Copyright (C) Institute of Research Engineers and Doctors, USA .All rights reserved.

ISBN: 978-1-63248-076-7 doi: 10.15224/ 978-1-63248-076-7-56

the service of quality and the satisfaction of the customers. When we look at the history of the libraries, Ranganathan [5]can be identified as the first person to pronounce the service quality concept. In 1931, he introduced the basic conception in library science as "Five laws of Library Science ". Library science researchers admit that the basic ideas on service quality and user satisfaction are inherent in it.

When we look at the researches done in the field of University libraries in Sri Lanka, it is apparent that researches done are very few. In comparison with the other countries, it appears there is dearth of research with regard to service quality. In literature reviews, information could be found of two researches conducted in Sri Lankan universities on service quality. One such research has been conducted by Library users of the University of Colombo to measure the service quality status. The other research has been conducted [6] only using students from four universities in only art faculties. It focused for service quality relation to user satisfaction. Although there are fifteen universities in Sri Lanka, only four universities were selected for this study. Its generalized results may not be covered all the subject streams. Since it covered only arts students other students might have separate perceptions regarding library services. One such research [7] has been conducted to assert the level of library services. To measure user expectations and satisfaction seven point Likert scale was used with " 1 " indicating "strongly disagree" and 7 indicating "strongly agree". Six hundred fourteen library users were randomly selected as respondent for this study. Modified SERQUAL model was used to get feedback from respondents to assess the actual services delivered by the university library. The author expected to identify the user perspectives of the service quality dimensions and to determine the overall service quality of the library system. The analysis of the research revealed that the users perceived and evaluated the overall service quality provided as determined mainly by six factors. In these two researches has been used revised Parasuraman's SERVQUAL model[8] .

\section{Statement of the Problem}

Certain studies confirmed that many library users keep away from using the libraries due to various reasons [9]. Since this is a great problem currently at hand, the professionals in this field must study current situation of library services of all the university libraries in Sri Lanka. Only then, we will be able to realize what is to be removed and what is to be added to the library services and to make sure that the money has been utilized properly. Then the recommendations can be adapted to introduce new attractive ways and means to improve the service quality of academic libraries in Sri Lanka.

Sri Lankan Government is spending vast sum of money for University libraries annually. The process of utilizing money differs from university to university. The number of readers and courses offered are considered as main measuring elements while allocating money for academic libraries. We must examine this scenario in order to understand whether they are satisfied or not with the service standard and quality of service.

It is the expectation of the Ministry of Higher Education to provide better library services to university students. Yet it is proved in the recent researches carried out, university students are not benefited comparing to the vast sum of funds spent by the government. There are complaints from university lecturers with regard academic libraries.

In this regard, new processes or modifications could be introduced after evaluation of the existing services in academic libraries. Certain studies have been conducted and have confirmed that many users of libraries keep away from using libraries due to various reasons at present [10]. As this is a critical problem, the professionals in the field should study the contemporary situation at hand in library services of all the university libraries in Sri Lanka. Subsequently the various measures can be adapted to introduce new ways and means to improve the service standards of academic libraries in Sri Lanka.

\section{Objectives}

The main objective of this research was to compare the service quality with user satisfaction in academic libraries in Sri Lanka. The attributes were identified to measure the service quality and satisfaction based on six main dimensions such as the physical facilities, library collection, library services, library services marketing, responsiveness of the library staff and the library web services. Additionally, below null hypothesis was formulated to test through this study.

"There is no any positive relationship between service quality and user satisfaction".

\section{Methodology}

In order to achieve above mentioned objective and other sub objectives, a questionnaire was designed and used to collect data for this study. 
Proc. of The Second Intl. Conf. On Advances In Economics, Social Science and Human Behaviour Study - ESSHBS 2015 Copyright (C) Institute of Research Engineers and Doctors, USA .All rights reserved.

ISBN: 978-1-63248-076-7 doi: 10.15224/ 978-1-63248-076-7-56

The key data for this study was obtained from Sri Lankan academic library users. For collecting data from the identified population, stratified random sampling was applied during the survey. One-way ANOVA, TUKEY's test, Post Hoc, Mean, Median and Mode were employed to test and analysis the data.

\section{Result and Discussion}

Special characteristics were identified during process of survey for service quality. It has decreased the standard of significant services necessarily available in libraries. In this analysis, all those necessary services that are vital for obtaining day to day fresh information and have been deteriorated in university libraries were found out. It was also identified that the mean median and mode scores of services/facilities such as ventilation in the library, relevant text books on various subjects, the range of printed journals, the range of e-journals, number of subscribed databases, opening hour of the library, number of service hours and printing facilities were between mean scores 3.000-2.000, median score 2.000 and mode scores between 1-2, and thus it was apparent that their standard was considerably low.

It was expected to measure the level of satisfaction of users about the library services. Results obtained in this research were also similar to that the results of service quality. The hypothesis developed in this research proved that there is a positive relationship between service quality and user satisfaction. Accordingly when there was low service quality, satisfaction of the users was also less. Same as when the user satisfaction was high, the service quality was also high. Only minor differences could be noticeable in both matters.

According to this analysis, some mean scores were found which were less than 3.00 and around almost 2.5 median between 3.000 to 2.000 and median 1 to 2 , which belonged to the factors such as ventilation in the library, text books on various subjects, range of printed journals, range of ejournals, number of subscribed databases, opening hour of the library, number of service hours and printing facilities opening hours had high influence on general satisfaction of the library users. It was found that the low service quality factors were similar to unsatisfied factors and it supported to prove hypothesis in this research. It was also found that satisfied factors which mean scores were greater than 3.00, mode value in 5 and they were not all similar to the service quality. But only a few factors such as check out system, order of books in shelves, user education program, new arrival notices, and reference desk for consultation and information notice board were similar to the service quality. As mentioned above while the service quality proliferates, user satisfaction follows it. This is very good evidence for any organization to be concerned in this regard.

The comparison was carried out in order to ascertain the status of service quality in university libraries under major six dimensions. The lists of major services provided were different from one university library to another. It was essential to find out separately the responses on service quality from users in each university. When quarried about service quality, it was felt tricky in finding out the varying situation in each university. Therefore, researcher has reviewed the attributes under six major dimensions separately. Subsequently it was found that how variations took place in all of these selected university libraries in each dimension. This will help the library authorities to take decisions to improve on service quality of their library. It was also observed that on certain dimensions, the services of some old university libraries have received remarkable improvements in their quality; at the same time the services of some newly established university libraries have decreased their quality. However, on certain occasions it was found that the services on some specific dimensions of newly established university libraries have come forward and provided better service quality.

Sometimes service quality and satisfaction are identified as an interrelated concept whereas some others identified the service quality as the other side of the satisfaction. It was stated that in a competitive business environment, customer satisfaction is a vital factor. Nonprofit organizations as well as profit oriented commercial establishments take efforts to measure service quality and satisfaction. Objective of these two concepts is ultimately to satisfy the customer. Customers' responses are considered as yardstick to gauge the services by any organization. In this context, the responses from the consumers are satisfied, it is a sign that the profit of that organization would go upwards. In the same manner authorities of libraries also take every endeavor to enhance their standard of services. Therefore, service quality and satisfaction are significant factors for a library as well as for any institute.

Due to the significance of these two concepts, researcher utilizing service quality and satisfaction developed a hypothesis. Accordingly "there is no any positive relationship between service quality and user satisfaction in academic libraries in Sri Lanka". Developed hypothesis was tested in data analysis. The hypothesis developed by the researcher was rejected by statistical analysis and as a result it was proved that "there is a positive 
Proc. of The Second Intl. Conf. On Advances In Economics, Social Science and Human Behaviour Study - ESSHBS 2015 Copyright (C) Institute of Research Engineers and Doctors, USA .All rights reserved.

ISBN: 978-1-63248-076-7 doi: 10.15224/ 978-1-63248-076-7-56

relationship between service quality and user satisfaction in academic libraries in Sri Lanka". The "P" values received for six dimensions were less than 0.05. Even though it was proved that there is a positive relationship between service quality and satisfaction, but it was a weak relationship.

This is an in-depth descriptive survey which was proposed to conduct in Sri Lanka to study service quality and user satisfaction in academic libraries. The research itself makes greater attention to identify current practices, trends, weaknesses, strengths and more with regard to the above theme and also it makes greater attention to identify the challenges and opportunities for the development of service quality and to increase the users' satisfaction. It is expected that the valuable comments and recommendations based on the findings of this research will assist experts and policy makers of the higher educational sector in Sri Lanka to make suitable decisions. Further the researcher strongly believes that the findings of this study will be a valuable source which can be used in various ways to develop university libraries and their services to fit with international academic library experiences.

\section{References}

[1] Quinn, B. (1997). “Adapting service quality concepts to academic libraries". Journal of academic librarianship, v.23, pp.359-369.

[2] Sirkin, A. (1993). "Customer service: another side of TQM". Journal Library Administration, v.8, pp.71-83.

[3] Carnegie, G., and West, B. (2003). "Placing monetary values on public repositories of knowledge: why, when and so what". The Council of Australian University Librarian Seminar.
[4] Nitecki, D. (1996). "Changing the concept and measure of service quality in academic libraries". Journal of Academic Librarianship, v.22(6), pp.181-190.

[5] Rangathan, S. R. (1988). "Five laws of library science". Bangalore: Sarada Endowment Scheme for Library Science.

[6] Jayasundara, C. C. (2011). "A modular approach to customer satisfaction in relation to service quality". Journal of the University Librarians' Association of Sri Lanka, v.15(1), pp.23-82.

[7] Somaratna, S. D., \& Peries, C. N. (2011). "Service quality in university of Colombo Libraries: an assessment". Annals of Library and Information Studies, v.58, pp.170-183.

[8] Parasuraman, A., Zeithmal, V., \& Berry, L. (1985). “A Conceptual model of service quality and its implication for future research". Journal of Marketing, v.49(4), pp. 41-50.

[9] Nawarathne, I. (2008). "Reading habits of undergraduates of Sri Lanka". International Symposium Proceeding of Sabaragamuwa University of Sri Lanka, pp.230232.

[10] Somarathne, S. (2010). "User expectations versus perception of service quality in University Libraries". ICULA 2010, Proceeding, pp.68-82.

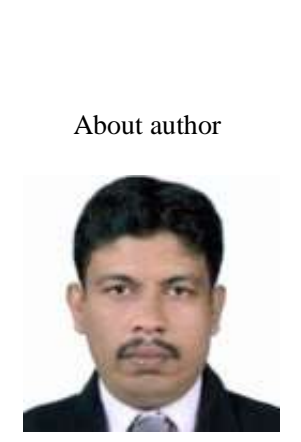

I.M. Nawarathne (B.A, Special, MLSc and $\mathrm{PhD}$ ) is a senior Assistant Librarian of the Sabaragamuwa University of Sri Lanka. He obtained his $\mathrm{PhD}$ in Library Science from Banaras Hindu University, India. He has published more than twenty research articles in the field of library science. He is a visiting lecturer of the Faculty of Social and Languages, Sabaragamua University of Sri Lanka. His major research areas are reading habit, Information literacy, and service quality and user satisfaction. 